\title{
Mobile Learning Apps in Instruction and Students Achievement
}

\author{
https://doi.org/10.3991/ijim.v11i1.6420 \\ Sandhya Kattayat \\ Higher Colleges of Technology, Abu Dhabi, UAE \\ sandhyamenon 24 @gmail.com \\ Smitha Josey \\ Higher Colleges of Technology, Abu Dhabi, UAE \\ vivianvarsha@gmail.com \\ Asha J.V \\ University of Kerala, Trivandrum, India \\ ashajv3@gmail.com
}

\begin{abstract}
Mobile learning technique is increasingly popular and is acting as a good instructional medium, How mobile learning apps enhances students achievement is investigated in this study. The students were divided in to two group and experimented. The result indicated that the students achievement is higher in the group who made use of mobile apps.
\end{abstract}

Keywords-Achievement, mobile apps, Physics.

\section{Introduction}

The increasing availability of low-cost mobile and wireless devices and associated infrastructure heralds both opportunities and challenges for educational institutions and their teachers and learners.[1]Mobile telephones are inexpensive, accessible, and well positioned for the delivery of student support interventions. Low cost mobile technologies can be used to maintain and enhance contact with students and teachers, and, by logic and improve retention[2]Students reasons for withdrawal from a course can be due to: distance from the study centres; insufficient academic support; insufficient information on counselling and laboratory sessions; and other associated information. As mobile phones become more ubiquitous, they are arguably well positioned to play a more central and effective role in providing students with much needed information - i.e., schedule of counselling and/ or laboratory sessions; and other relevant information related to their studies.[3]Most learning pedagogies from constructive learning and conversation theories can be adapted for a mobile learning environment. The key is to understand the strengths and weakness of a particular technology, while deploying good pedagogical practices to achieve specific learning goals.[3]It seems inevitable that m-learning will soon be an essential extension of e- 
learning[3] In the context of mobile learning, device type has a critical impact on teaching and learning.[4] Mobile learning is most prevalent at higher education institutions, followed by elementary schools. Mobile learning most frequently supports students in the professions and applied sciences, followed by the humanities and formal sciences. The most highly cited articles fall into the categories of mobile learning system design and followed by effectiveness. In sum, this study of issues in mobile learning presents findings which can help supplement linkages with previous studies and forms an important reference base for the future research in mobile learning.[4]The basic elements of mobile learning are teacher, learner, content, environment and assessment.[7]

\section{$2 \quad$ Research Problem}

This study is aimed to determine 'how' mobile technologies can be used to improve students' achievement. This study aims to find the relationship between these two variables. Mobile learning has different characteristics. The core characteristic of mobile learning are ubiquitous, portable size of mobile tools, blended, private, interactive, collaborative, and instant information[7].

\section{Research Methodology}

\subsection{Design of the experimental method.}

An experimental methodology is used in this study. The sample selected was senior Engineering students from Trivandrum, India. There were 48 students of first semester electronic engineering students taken for this study. A pretest was developed in one of their subject Applied Physics. This was administered and the equivalency of the students were ensured. Then students were grouped into two groups, experimental group and traditional learning group based on their pretest results in Physics. Each group consists of 24 students each. Mobile apps were used to teach the experimental group. The other group was taught in the traditional way. This was used for 4 topics in Physics extending to 4 days. Then a post test was given to students of each group in these topics. The results were analyzed using $t$ test and $p$ values.

\subsection{Mobile apps used for instruction}

The following mobile apps were used for instruction in experimental group.

Physics Tutor app: The focus of the app is to help student to solve mathematical problems in physics. This app will help them to concentrate on the concepts, without having to worry about the Mathematics involved in it. It has the features like Equation Calculator and graphing tool and provides link to wikipedia. Equation calculator will solve the equation and will provide complete step-by-step details of a problem. Gra- 
phing tool will plot a graph and gives an overview in understanding how one Physical Quantity varies with another.

Physics Cheater: This app provides quick information about the theories Physics Cheat Sheets: Gives very detailed information on almost all branches of physics. It has been thought out as a quick reference guide.

Physics One Apps This app is packed full of information, nicely structured and a very good resource for any student who is in need of some great physics information.

\subsection{Tools and mathematical methods used for measurement}

There are two tools used in this study. One is the pretest question paper which is used to ensure the equality of the students. The second one is the posttest question paper in the subject Physics which consists of 28 questions related to the topics taught in Physics. The pre and post tests were designed by considering expert opinion. The post test was administered to both groups at the same time. The student's responses were collected and analyzed using mean median, standard deviation, $t$ test values and $\mathrm{p}$ values. The results of both groups were compared.

\section{$4 \quad$ Results}

\subsection{Analysis of Pretest result}

The pretest is to ensure the equivalency of the two groups. Statistical technique used is $t$ test. The $t$ value obtained after administration of pretest can be interpreted. The low value of $\mathrm{p}$ shows that the two groups are of same level and it is not by chance.

Table 1.

\begin{tabular}{|c|c|c|c|c|c|c|c|c|c|}
\hline Discipline & $\begin{array}{l}\text { Sample } \\
\text { Group }\end{array}$ & Mean & SD & $\begin{array}{c}\text { Confidence } \\
\text { interval }\end{array}$ & $\begin{array}{c}\text { Difference } \\
\text { of means }\end{array}$ & $\begin{array}{c}\text { Significance } \\
\text { at } 95 \% \\
\text { confidence }\end{array}$ & median & $\begin{array}{c}\mathbf{t} \\
\text { value }\end{array}$ & $\begin{array}{c}P \\
\text { vale }\end{array}$ \\
\hline \multirow{2}{*}{ Physics } & Group 1 & 75.167 & 16.62 & $\begin{array}{l}68.961- \\
81.373\end{array}$ & \multirow[t]{2}{*}{0.933} & \multirow[t]{2}{*}{$\begin{array}{l}\text { No signifi- } \\
\text { cant differ- } \\
\text { ence }\end{array}$} & 78.0 & \multirow[t]{2}{*}{0.220} & \multirow[t]{2}{*}{0.83} \\
\hline & Group 2 & 74.233 & 16.194 & $\begin{array}{l}68.186- \\
80.28\end{array}$ & & & 74.5 & & \\
\hline
\end{tabular}

\subsection{Analysis of Post test result}

The post test is to ensure the equivalency of the two groups. Statistical technique used is $t$ test. The $t$ value obtained after administration of pretest can be interpreted. The $p$ value is 0.014 which shows that mobile learning technique enhances the students' achievement. 
Table 2.

\begin{tabular}{|c|c|c|c|c|c|c|c|c|c|}
\hline Discipline & $\begin{array}{l}\text { Sample } \\
\text { groups }\end{array}$ & Mean & SD & $\begin{array}{c}\text { Confidence } \\
\text { interval }\end{array}$ & $\begin{array}{c}\text { Difference } \\
\text { of means }\end{array}$ & $\begin{array}{l}\text { Significance } \\
\text { at } 95 \% \\
\text { confidence }\end{array}$ & median & $\begin{array}{c}\mathrm{t} \\
\text { value }\end{array}$ & $P$ vale \\
\hline \multirow{2}{*}{ Physics } & Group 1 & 62.433 & 10.881 & $\begin{array}{l}58.37- \\
66.496\end{array}$ & \multirow[t]{2}{*}{-8.233} & \multirow[t]{2}{*}{$\begin{array}{c}\text { Sample2 } \\
\text { mean is } \\
\text { grater }\end{array}$} & 66.0 & \multirow[t]{2}{*}{2.54} & \multirow[t]{2}{*}{0.014} \\
\hline & Group 2 & 70.667 & 14.062 & $\begin{array}{l}65.416- \\
75.912\end{array}$ & & & 73.5 & & \\
\hline
\end{tabular}

\section{Conclusion}

The aim of the study is to determine the effect of instruction using mobile apps on student's achievement. Instruction using mobile apps is used to evaluate the effectiveness of learning and thus the achievements of students. In order to get efficient results and the maximum performance from students using mobile learning in education, each of the elements of mobile learning should be prepared carefully, and the mobile learning characteristics should be planned and prepared with a knowledge of the teaching medium, learning environment and the learning activities. Otherwise, positive results cannot be expected from the mobile application.[7] The power of mlearning technology can be leveraged by complimenting the existing courses with value-added features such as alerts, personalized agents or communications aids, and access to interaction or discussion utilities that help users convert their dead-time to productive activity while in transit without an access to computers and Internet.[3]. A conceptual framework for the design of mobile learning should ensure the achievement of learner- centered, highly situated, personal and collaborative mobile learning.[6]Students in both the traditional learning group and the experimental group spent the same time to complete their learning tasks. The results show that the teaching learning process using mobile apps is helpful to the students in improving their learning achievements.

\section{Recommendation}

Mobile learning has many advantages such as to improve literacy and numeric skills, can be used for independent and collaborative learning experiences, helps learners to identify where they need assistance and support, helps to overcome the digital divide, to make learning informal, helps learners to be more focused for longer periods, to raise self-esteem and self-confidence [8] Low cost mobile technologies can be used to maintain and enhance contact with students and teachers.[2]. This study can be extended to explore other aspects of instruction such as distance learning and advanced online learning. This can be used as a good method for home schooling as smartphones are more and more cheaper day by day. 


\section{$7 \quad$ References}

1. Cobcroft, Rachel S and Towers, Stephen and Smith, Judith and Bruns, Axel (2006) Mobile learning in review: Opportunities and challenges for learners, teachers, and institutions. In Proceedings Online Learning and Teaching (OLT) Conference 2006, pages pp. 21-30, Queensland University of Technology, Brisbane.

2. Bharat Inder Fozdar \& Lalita S. Kumar International Review of Research in Open and Distance Learning,Volume 8, Number 2. ISSN: 1492-3831,June - 2007

3. Mobile learning: A framework and evaluation, Luvai F. Motiwalla, Computers \& Education 49 (2007) 581-596 https://doi.org/10.1016/j.compedu.2005.10.011

4. Wen-Hsiung $\mathrm{Wu}$, Yen-Chun Jim Wu, Chun-Yu Chen, Hao-Yun Kao, Che-Hung Lin ,Sih-Han Huang, Review of trends from mobile learning studies: A meta-analysis, Computers \& Education 59 (2012) 817-827 https://doi.org/10.1016/j.compedu.2012.03.016

5. Manuela Paechter *, Brigitte Maier, Daniel Macher,(2009),Students' expectations of, and experiences in e-learning: Their relation to learning achievements and course satisfaction, Computers \& Education

6. Naismith, L., Lonsdale, P., Vavoula, G., \& Sharples, M. (2004). NESTA Futurelab Report 11: Literature review in mobile technologies and learning. Bristol, UK: NESTA Futurelab. Retrieved December 27, 2005, from http://www.nestafuturelab.org/research/reviews/ reviews_11_and12/11_01.htm

7. Fezile Ozdamli, Nadire Cavus, Basic elements and characteristics of mobile learning, Procedia - Social and Behavioral Sciences 28 (2011) 937 - 942 https://doi.org/10.1016/ j.sbspro.2011.11.173

8. Attewell, J., \& Savill-Smityh, C. (2003). m-Learning and Social Inclusion: Focusing on learners and learning. Proceeding of MLEARN 2003: Learning with mobile devices (pp. 312). London: Learning and Skillls Development Agency.

\section{Authors}

Sandhya Kattayat is with Higher colleges of Technology, Abudhabi, UAE. She is with the Department of Physics. (e-mail: sandhyamenon24@gmail.com).

Smitha Josey is with Higher colleges of Technology, Fujairah, UAE. She is with the Department of Eng. Tech \& Science. (e-mail: vivianvarsha@gmail.com).

Asha J. V. is the Hon. Director of Curriculum Development and Asst. Professor (Education), in University of Kerala. (e-mail: ashajv3@gmail.com).

This work was financially supported in part by HCT.

Submitted, 14 November 2016. Published as resubmitted by the authors on 30 December 2016 